\title{
Structural Properties of the Brazilian Air Transportation Network
}

\author{
GUILHERME S. COUTO ${ }^{1}$, ANA PAULA COUTO DA SILVA ${ }^{2}$, \\ LINNYER B. RUIZ ${ }^{1}$ and FABRÍCIO BENEVENUTO ${ }^{2}$ \\ ${ }^{1}$ Universidade Estadual de Maringá, Centro de Tecnologia, Departamento de Informática, \\ Avenida Colombo, 5790, 87020-900 Maringá, PR, Brasil \\ ${ }^{2}$ Departamento de Ciência da Computação, Universidade Federal de Minas Gerais, \\ Avenida Antônio Carlos, 6627, Pampulha, 31270-010 Belo Horizonte, MG, Brasil \\ Manuscript received on March 31, 2014; accepted for publication on March 9, 2015
}

\begin{abstract}
The air transportation network in a country has a great impact on the local, national and global economy. In this paper, we analyze the air transportation network in Brazil with complex network features to better understand its characteristics. In our analysis, we built networks composed either by national or by international flights. We also consider the network when both types of flights are put together. Interesting conclusions emerge from our analysis. For instance, Viracopos Airport (Campinas City) is the most central and connected airport on the national flights network. Any operational problem in this airport separates the Brazilian national network into six distinct subnetworks. Moreover, the Brazilian air transportation network exhibits small world characteristics and national connections network follows a power law distribution. Therefore, our analysis sheds light on the current Brazilian air transportation infrastructure, bringing a novel understanding that may help face the recent fast growth in the usage of the Brazilian transport network.
\end{abstract}

Key words: Brazilian air transportation network, network science, structural network analysis, complex networks.

\section{INTRODUCTION}

Transport networks play an important role on the daily lives of populations. In addition to the impact on the country's economy as well as on its development, transport networks improve people's quality of life. Among all transport networks, air transportation network is one of the most important, connecting people in a fast and safe way. In some countries, such as the USA, the use of airplanes to travel from place to place comes from many decades ago. However,

Correpondence to: Ana Paula Couto da Silva

E-mail: ana.coutosilva@dcc.ufmg.br some countries experimented an explosion on using air transportation system only few years ago (ANAC 2013).

Brazil is an example of a country that has had an impressive growth in the usage of the air transportation network in the last 10 years. This growth is due to two main factors: the improvement of Brazilian family income and the decrease of the price of airline tickets. In 2003, 37.2 million passengers flew (29 million and 8 million passengers for national and international flights, respectively). In 2012, the number of passengers increased to 107 million $(\approx 89$ million and 18 
million passengers for national and international flights, respectively). Likewise, the total number of flights almost doubled from 611,091 flights in 2003 (534 thousand national flights and 76 thousand international flights) to $1,126,907$ flights in 2012 (989 thousand national flights and 137 thousand international flights) (ANAC 2013).

As the most of air transportation networks, the Brazilian network has a complex structure, with dozens of airports and airline companies, operating thousand of national and international flights. Understanding the underlying structural properties of this network is crucial to properly face its fast growth in the last years. Some of the challenges to be faced are, for instance, modernize the airports' infrastructure that are outdated and establish better flight routes in order to improve the quality (Pacheco and Fernandes 2003).

Even though there are many governmental analysis on this topic, we believe that an analysis of the Brazilian air transportation structure, at a network level, is still lacking. The overall analysis of the network enables the identification of the most important and central airports, as well as, the infrastructure robustness under airports fail due to, for instance, weather conditions. Furthermore, it is not clear how the properties of the Brazilian air transportation network compare with other country networks. A complex network analysis (Newman 2003, Reka and Barabási 2002) provides an ideal framework to pursue such a study. To the best of our knowledge, this is the first study that provides a deeper analysis of the Brazilian air transportation using a large number of complex networks features.

For that purpose, we have collected data from Agência Nacional de Aviação Civil (ANAC) ${ }^{1}$, the civil aviation authority that is responsible for regulating the air transport in Brazil. We built three networks of nodes (representing the airports) and established links between pairs of airports

${ }^{1}$ www.anac.gov.br connected by flights of 51 airline companies that operate in the Brazilian airspace (including the four largest Brazilian airline companies: TAM, Gol/Webjet, Azul/Trip, Avianca). We hope that our analysis sheds light on the current Brazilian air transportation infrastructure, bringing a novel perspective to understanding its main properties and characteristics. Our main findings are:

- The Brazilian Air Transportation Network exhibits small world characteristics with low average shortest path length and high clustering coefficient;

- Airport connections follow a power law distribution, with few hubs connected to many low-degree neighbors;

- Viracopos Airport (Campinas City) is the most connected and central airport in the national flights network, being part of a large number of shortest routes;

- Brazilian travelers need, on average, 3 connection flights to reach their destinations. The maximum number of connections is 7 , from Confresa Airport (state of Mato Grosso) to Pato de Minas Airport (state of Minas Gerais);

- The most central airports are concentrated on the Southest and on the Brazilian coastal region. To reach cities not in these regions many hops are mandatory;

- Viracopos Airport outage breaks the network into 6 subnetworks, affecting $10 \%$ of the passengers.

The rest of the paper is organized as follows. In Section 2 (See Related Work), we review the main results found on air transportation networks characterization. Afterward, we describe the data we collected and how we modeled the air transportation network in Section 3 (See The Air Transportation Network). In Section 4 (See Air Transportation Network Analysis and Discussion) we discuss our results and their implications. Lastly, in Section 5 (See Conclusions), we present our main conclusions and directions for future work. 


\section{RELATED WORK}

Several papers in the literature have devoted their attention to characterizing and analyzing the airline network from a national and worldwide point of view. In (Guimer et al. 2005) authors analyzed the global structure of the worldwide air transportation network. They found that the worldwide air transportation network follows a scale-free and small-world characteristics and the most connected cities are not necessarily the most central ones. Furthermore, authors identified each global role of a city based on its pattern of intercommunity and intracommunity connections. This result enabled the creation of a scale-specific representation of the whole network.

The main purpose of (Cheung and Gunes 2012) was to analyze the social network features of the U.S. air transportation network. Authors showed that the network exhibits small-world characteristics and, on average, travelers experienced 2 transfers before reaching their destinations. Over the past two decades, network has grown through the years as the number of airports and the number of flight routes between airports has increased to meet customer demands. They also show that the air transportation network, unlike other examples of networks, has only a partial power law degree distribution.

Authors in (Bagler 2008), instead, analyzed the air transportation network in India. This network also has a small-world characteristic, with some airports acting as hubs connected to low-degree neighbors. Chinese airport network is analyzed in ( $\mathrm{Li}$ and Cai 2004) and it also follows a small-world model. Interestingly, the cumulative degree distributions of both directed and undirected networks obey tworegime power laws with different exponents.

The Italian Airport Network was analyzed in (Guida and Maria 2007). The topological properties of the resulting network have been examined leading to the confirmation of a scale- free behavior in the connection distribution. However, the scale-free behavior turned out to be a little bit different from the ones already reported, suggesting that the growth mechanism model underlying the network could be different from the ones proposed so far. This consideration is due to the fact that the outcomes of the investigation strongly suggest a fractal structure for this network. Moreover, the paper shows that the clustering coefficient is rather comparable or a little bit smaller than those for a random network, differently from what occurs to some other, where the clustering coefficients are larger than the corresponding random values.

Some works that analyze the Brazilian air transportation network can be found in (Pacheco and Fernandes 2003, Costa et al. 2010, Oliveira et al. 2013). Authors in (Pacheco and Fernandes 2003) analyzed how to improve the infrastructure of Brazilian airports. Authors in (Costa et al. 2010) pointed out how many hubs the Brazilian air transportation network should have to improve its infrastructure quality. Furthermore, authors also indicated the main airports which should be transformed into hubs.

The results more in line with our work are presented in (Oliveira et al. 2013). In that work, authors analyze the Brazilian air transportation system. However, differently of our focus on analyzing the global and local characteristic of the network topology, authors focus on studying the hub organization of airports in Brazil. They show that Guarulhos Airport in São Paulo (GRU) has a crucial role in terms of number of flights and connections. Then, they investigated the robustness of the network with a single hub, by analyzing the impact of the removal of GRU from the network.

Overall, to the best of our knowledge, a network analysis about the Brazilian airport system is missing in the literature. Thus, our work is complementary to the (Pacheco and Fernandes 2003, Costa et al. 2010, Oliveira et al. 2013) efforts. 


\section{THE AIR TRANSPORTATION NETWORK}

\section{DATASET}

Many measures - including total number of passengers, total number of flights, or total amount of cargo - quantifying the importance of Brazilian airports are compiled and publicized in the Agência Nacional de Aviação Civil (ANAC) website ${ }^{2}$. Data is organized in updated spreadsheets with information about authorized national and international flights ${ }^{3}$.

We restrict our analysis to passenger flights operating according to the data provided in October $20,2013^{4}$. As flights do not have significant changes, we can assume that we are using a stable view of the airline network, based on the weekly information. At that time, there were 3, 579 national (interstate and intrastate flights) and 419 international flights, respectively. The total number of Brazilian airports is 120,15 of them operating both national and international flights. A total number of 53 foreign airports have flights to/from Brazil. The total number of passengers on each flight is the maximum number of allowed passengers on each flight. We do not have access to the number of occupied seats for a specific flight. Therefore, here we present the upper bound values with respect to the maximum passenger capacity in each flight.

Some Brazilian airports found in the spreadsheets are shown in Table I. It shows the ICAO $\operatorname{code}^{5}$, the airport name and the city of the airport. An additional information ${ }^{6}$ was inserted in Table I to better analyze the air transportation network: the Instrument Landing System (ILS) ${ }^{7}$. This instrument helps pilots in landing operations and it is generally used only when visibility is limited and the pilot cannot see the airport and the runway. The system is divided into three categories of approach from I to III. In "CAT I" ILS, for instance, pilot needs to have at least $200 \mathrm{ft}$ of decision height and 1,600 ft of visibility. In "CAT IIIc" ILS, instead, pilot can land in any visibility condition. So far, Brazilian airports are not equipped with the safest ILS instrument. In this sense, Brazilian airports tend to be more vulnerable to bad weather conditions.

NETWORK MODELS

We focus our analysis on three scenarios that enable us to better characterize the Brazilian airport infrastructure, as well as to characterize the types of flights offered to the population. Although we present a more detailed analysis considering national connections, we also provide insights on international connections. Furthermore, we analyze a network model including both national and international connections. All metrics we used are usual metrics of complex network analysis (Newman 2003, Reka and Barabási 2002). We represented the Brazilian airport network as a directed graph $\mathcal{G}(\mathcal{V}, \mathcal{E})$, where $\mathcal{V}$ is the set of airports and $\mathcal{E}$ is the set of links. A link between two airports exists if there is at least one flight from one airport to another. Here, we consider two versions of graph $\mathcal{G}$ : the unweighted and the weighted one. It is worth noting that we use the weighted version of each graph only for calculating the maximum number of passengers metric. (In this case, the maximum number of passengers is the link weight).

\footnotetext{
${ }^{2}$ http://www2.anac.gov.br/hotran/. Additional information can be found in http://www.infraero.gov.br/index.php/situacao-dosvoos/por-aeroporto.html

${ }^{3}$ Stop flights were considered as a set of individual flights

${ }^{4} 20$ th to 26 th-October week

${ }^{5}$ The International Civil Aviation Organization Code assigned to distinguish uniquely each airport

${ }^{6}$ Obtained at http://www.aisweb.aer.mil.br/?i=cartas\&filtro $=1 \&$ nova $=1$

${ }^{7}$ http://en.wikipedia.org/wiki/Instrument_landing_system
} 
TABLE I

Main Brazilian Airports.

\begin{tabular}{c|c|c|c}
\hline ICAO & Airport Name & City/State & ILS \\
\hline SBGR & Governador André Franco Montoro & Guarulhos/SP & CAT II \\
\hline SBKP & Viracopos & Campinas/SP & CAT I \\
\hline SBGL & Galeão - Antônio Carlos Jobim & Rio de Janeiro/RJ & CAT II \\
\hline SBBR & Presidente Juscelino Kubitschek & Brasília/DF & CAT II \\
\hline SBCF & Tancredo Neves & Belo Horizonte/MG & CAT I \\
\hline SBSV & Deputado Luís Eduardo Magalhães & Salvador/BA & CAT I \\
\hline SBPA & Salgado Filho & Porto Alegre/RS & CAT I \\
\hline SBSP & Congonhas & São Paulo/SP & CAT I \\
\hline SBCT & Afonso Pena & Curitiba/PR & CAT II \\
\hline SBRF & Gilberto Freyre & Recife/PE & CAT I \\
\hline SBCY & Marechal Rondon & Cuiabá/MT & CAT I \\
\hline SBEG & Eduardo Gomes & Manaus/AM & CAT I \\
\hline SBRJ & Santos Dumont & Fortaleza/CE & CAT I \\
\hline SBFZ & Pinto Martins & Belém/PA & CAT I \\
\hline SBBE & Val de Cães/Júlio Cezar Ribeiro & Ribeirão Preto/SP & - \\
\hline SBRP & Leite Lopes & Goiânia/GO & - \\
\hline SBGO & Santa Genoveva & Campo Grande/MS & CAT I \\
\hline SBCG & Campo Grande & Natal/RN & CAT I \\
\hline SBNT & Augusto Severo &
\end{tabular}

${ }^{a}$ Guarulhos has CAT IIIa installed since 2011 but to date is still not certified.

TABLE II

Number of nodes and edges for each connection network.

\begin{tabular}{c|c|c}
\hline Scenario & Nodes & Edges \\
\hline $\mathcal{G}_{\text {national }}$ & 120 & 726 \\
\hline $\mathcal{G}_{\text {international }}$ & 68 & 222 \\
\hline $\mathcal{G}_{\text {overall }}$ & 173 & 948 \\
\hline
\end{tabular}

We consider three different network models: $\mathcal{G}_{\text {national }}$ with national flights, $\mathcal{G}_{\text {international }}$ with international flights and $\mathcal{G}_{\text {overall }}$, considering both national and international flights. Table II presents the total number of nodes (airports) and links (connections) on each graph.

\section{NETWORK METRICS}

We characterize the Brazilian air transportation network using classical graph theory metrics (a more detailed discussion on each metric can be found in (Newman 2003, Reka and Barabási 2002)). We used the interactive open source graph visualization and manipulation platform software Gephi (Bastian et al. 2009) for rebuilding and analyzing the graph we modeled.

\section{In-degree and out-degree}

The in-degree of node $v, k_{i n}(v)$, is the total number of incoming links. In the same way, the out-degree of node $v, k_{\text {out }}(v)$ is the total number of outgoing links. Then, the degree of node $v, k(v)$, is given by the summation of $k_{i n}(v)$ and $k_{\text {out }}(v)$. The mean degree, $<k>$, of a $\mathcal{G}$ is given by:

$$
<k>(\mathcal{G})=\sum_{\forall v \in \mathcal{V}} k(v) /|\mathcal{V}| .
$$

Weighted in and out degrees are a straightforward definition of the unweighted version.

\section{Average neighborhood overlap}

Let $\mathcal{N}(u)$ and $\mathcal{N}(v)$ be the set of neighbors of nodes $\mathrm{u}$ and $\mathrm{v}$, respectively. The neighborhood overlap, $n_{o}(u, v)$ of nodes $\mathrm{u}$ and $\mathrm{v}$, is given by:

$$
n_{o}(u, v)=(\mathcal{N}(u) \cap \mathcal{N}(v)) /(\mathcal{N}(u) \cup \mathcal{N}(v)),
$$


also know as Jaccard Coefficient. Then, the average neighborhood overlap is given by:

$$
<n_{o}>=\frac{1}{|\mathcal{E}|} \sum_{\forall(u, v) \in \mathcal{E}} n_{o}(u, v) .
$$

\section{Shortest path}

Let $P_{u, v}$ be the set of paths between a given pair of nodes $u$ and $v$. We define the shortest path $l(u, v)$ as the one having the lowest number of hops between source and destination. Let be also $L$ the set of all shortest paths $l(u, v), \forall(u, v)$. The mean shortest path $<l>$, of a graph $\mathcal{G}$ is given by:

\section{Diameter}

$$
<l>(\mathcal{G})=\frac{1}{|\mathcal{L}|} \sum_{\forall l(u, v) \in \mathcal{L}} l(u, v) .
$$

Let $l(u, v)$ be the shortest path between nodes $u$ and $v$. Diameter, $\mathbf{d}$, is defined as the longest shortest path between any pair of nodes in the network:

$$
\mathbf{d}(\mathcal{G})=\max _{\forall(u, v) \in \mathcal{V}} l(u, v) .
$$

Diameter property provides an idea of the dispersion in $\mathcal{G}$. In the air transportation network, diameter measure means the biggest trip in number of hops.

\section{Clustering coefficient}

We define the clustering coefficient, also known as network transitivity, as follows. In many networks, if node A is connected to node B and node B to node $C$, then there is a heightened probability that node $\mathrm{A}$ will also be connected to node $\mathrm{C}$. In terms of network topology, transitivity means the presence of a heightened number of triangles in the network, i.e., sets of 3 nodes connected to each other. We define the clustering coefficient $\mathcal{C}$ of $\mathcal{G}$ as:

$$
\mathcal{C}(\mathcal{G})=\frac{3 \times \text { number of triangles in the network }}{\text { number of connected triples of vertices }}
$$

Where a "connected triple" means a single node with edges running to an unordered pair of others.

\section{Betweenness}

The betweenness $\beta_{v}$ of node $v$ is the fraction of shortest paths connecting all pairs of nodes that pass through $v$. In other words, let $\sigma_{(j, k)}$ represent the number of shortest paths between nodes $j$ and $k$, and $\sigma_{(j, k)}(v)$ the number of those paths that traverse node $v$. The betweenness of $v$ is thus defined as:

$$
\beta(v)=\sum_{j \neq v \neq k \in \mathcal{V}} \frac{\sigma_{(j, k)}(v)}{\sigma_{(j, k)}} .
$$

\section{Closeness}

The closeness $\gamma_{v}$ of node $v$ captures how close it is from all other reachable nodes in the network. Given $\pi(v, k)$, the length of the shortest path between $v$ and any other reachable node $k, \gamma_{v}$ is defined as:

$$
\gamma(v)=\left[\sum_{k \neq v, k \in \mathcal{V}} \pi(v, k)\right]^{-1} .
$$

\section{PageRank}

PageRank is an algorithm used by the Google web search engine to rank websites in their search engine results. PageRank works by counting the number and quality of links to a node to determine a rough estimate of how important the node is. The underlying assumption is that more important nodes are likely to receive more links from other nodes (Brin and Page 1998). In the air transportation network it can assess which airport is more influent than others. The rank of a node $P_{i}$ is given by the sum of all node ranks that point to node $P_{i}$ divided by the number of nodes $P_{i}$ points to:

$$
\begin{gathered}
r\left(P_{i}\right)=\sum_{P_{j} \in B_{P_{i}}} \frac{r\left(P_{j}\right)}{\left|P_{j}\right|}, \\
r_{k+1}\left(P_{i}\right)=\sum_{P_{j} \in B_{P_{i}}} \frac{r_{k}\left(P_{j}\right)}{\left|P_{j}\right|} .
\end{gathered}
$$

PageRank definition is recursive, and the process is iterated many times ${ }^{8}$.

\footnotetext{
${ }^{8}$ Results shown in Section 4 (See Air Transportation Network Analysis and Discussion) are normalized.
} 


\section{Graph density}

The graph density $D$ is defined as a ratio of the number of edges $|\mathcal{E}|$ to the number of possible edges (considering the complete graph):

$$
D=2|\mathcal{E}| /(|\mathcal{V}|(|\mathcal{V}|-1))
$$

\section{Connected component of the graph}

A directed graph is strongly connected if every node is reachable from every other node. In this sense, the strongly connected components of an arbitrary directed graph form a partition into subgraphs that are themselves strongly connected.

TABLE III

Metrics of different Air Transportation Networks.

\begin{tabular}{c|c|c|c|c|c|c}
\hline & Worldwide $^{a}$ & India $^{b}$ & China $^{c}$ & USA $^{d}$ & Italy $^{e}$ & BRAZIL $^{f}$ \\
\hline Average Shortest Path & 4.4 & 4 & 2.067 & 3.241 & 3.74 & $\mathbf{2 . 8 6 6}$ \\
\hline Average Clustering & 0.62 & 0.6574 & 0.733 & 0.6208 & 0.1 & $\mathbf{0 . 4 5 1}$ \\
\hline Power Law Exponent & 1.0 & $\approx 2.2$ & 1.65 & Partial $1.0512^{g}$ & $0.2 / 1.7^{h}$ & $\mathbf{1 . 0 5 2 2}$ \\
\hline
\end{tabular}

${ }^{a}$ (Guimer et al. 2005), ${ }^{b}$ (Bagler 2008), ${ }^{c}$ (Li and Cai 2004), ${ }^{d}$ (Cheung and Gunes 2012), ${ }^{e}$ (Guida and Maria 2007), ${ }^{f}$ Our results, ${ }^{g}$ Degree distribution function is a mixed distribution, ${ }^{h}$ Degree distribution is a combination of two power law distribution functions with coefficients equal to 0.2 and 1.7 .

\section{AIR TRANSPORTATION NETWORK}

\section{ANALYSIS AND DISCUSSION}

This section describes the results obtained from the analysis of our database. First, the Brazilian air transportation network is compared with other country's airplane networks previously analyzed in the literature. Then, a more detailed analysis about the national flights is presented indicating some characteristics of the Brazilian air transportation network. Moreover, we show the community formation and the resiliency analysis of the Brazilian network. Finally the International and the Overall view of the Brazilian airports network is presented showing some peculiarities of the network, such as to which international airports Brazil is connected.

\section{BRAZILIAN AIR TRANSPORTATION NETWORK VERSUS}

\section{FOREIGN AIR TRANSPORTATION NETWORKS}

Table III shows the comparison of Brazilian airline network against the set of foreign networks found in literature (Guimer et al. 2005, Bagler 2008, Li and Cai 2004, Cheung and Gunes 2012, Guida and Maria 2007). To provide a better comparison among the characteristics of different airline networks, Table IV shows some indicators of each country we show in Table III, considering the year of the dataset analyzed in each work found in literature.

First we can note that node degree on the $\mathcal{G}_{\text {national }}$ follows a power law, which means that there are few airports with many connections and many airports with few connections. Such network, whose degree

TABLE IV

Some important indicators of each country.

\begin{tabular}{c|c|c|c|c}
\hline Country & Population & Area $\left.\mathbf{( k m}^{\mathbf{2}}\right)$ & Airports & Gross Domestic Product \\
\hline India & $1.110 \mathrm{bi}$ & $2.973 \mathrm{mi}$ & 79 & U\$\$721.585 bi \\
\hline China & $1.296 \mathrm{bi}$ & $9.327 \mathrm{mi}$ & 128 & U\$\$ $1.931 \mathrm{tri}$ \\
\hline USA & $311.587 \mathrm{mi}$ & $9.147 \mathrm{mi}$ & 850 & U\$\$ $15.533 \mathrm{tri}$ \\
\hline Italy & $58.94 \mathrm{mi}$ & 294,140 & 42 & U\$\$ $1.873 \mathrm{tri}$ \\
\hline Brazil & $201.032 \mathrm{mi}$ & $8.459 \mathrm{mi}$ & 120 & U\$\$2.242 tri \\
\hline
\end{tabular}


distribution follows a power law, is called scale-free network. Second, the average shortest path is also low, with few hops to move from place to place. Furthermore, the Brazilian network has lower average clustering value, in comparison to the others. This implies that there are fewer triangles in the network, leading to a low redundancy in paths between airports. From indicators showed in Table IV, we can note that Brazil has a larger number of airports per capita than India and China. USA, as expected, is the country with the most airports, mainly because of its area and its economic power. However, considering only the topological metrics, results reveal that the Brazilian airline network follows a similar structure when compared to other airlines network.

\section{NATIONAL NETWORK CHARACTERISTICS}

Next, we consider the 3,579 national flights operated by the airline companies as well as the 120 airports in which flights take off from and land at. In this sense, the national graph version of $\mathcal{G}$ has 120 nodes and 726 links. The maximum number of passengers that can move per week is equal to $2,631,836$. In other words, this number is the total number of passengers in the case that all flights were completely full. Table V shows the global metrics. We found some interesting conclusions. The generated graph is connected, meaning that it is possible to reach all airports from another. Airport connectivity is low: on average, each airport connects to another 6 airports (5\% of total number of nodes). In the United States, for instance, the mean of connections is 24 airports but it only represents $2.8 \%$ of the total number of airports. Furthermore, the average neighborhood overlap is equal to 0.163 . Edges with very small neighborhood overlap act as local bridges, since intuitively, edges with very small neighborhood consist of nodes that span over different regions of the graph. In this sense, the value of neighborhood overlap of the Brazilian airline infrastructure reveals that the network is composed by many airports that act as bridges. This kind of infrastructure directly impacts on the network connectivity: a removal of an edge can make an increasing on the number of trip hops to a particular destination or, even worst, to disconnect the network.

TABLE V

Network metrics - National Flights.

\begin{tabular}{c|c}
\hline Network Measure & Value \\
\hline Connected Components & $1(120$ airports $)$ \\
\hline Average Connections & $6.05(5 \%)$ \\
\hline Average Weighted Degree & 21,932 \\
\hline Diameter & 7 \\
\hline Average Shortest Path & 2.866 \\
\hline Graph Density & 0.051 \\
\hline Average Clustering Coefficient & 0.451 \\
\hline Average Neighborhood Overlap & 0.163 \\
\hline
\end{tabular}

Passengers in Brazil take, on average, 3 flights to move from place to place (the average shortest path is equal to 2.86). Interestingly, the largest trip in Brazil has 7 flights (diameter graph) and is the trip from Confresa Airport (sate of Mato Grosso) to Pato de Minas Airport (state of Minas Gerais) (cities are just $1,472 \mathrm{~km}$ apart from each other). Finally, the average clustering coefficient is 0.451 . This implies that an airport has $45 \%$ of chance to be connected to another airport in the network. Lastly, the maximum number of passengers that can fly every week is, on average, equal to 21, 932 per airport.

To provide a deeper analysis, we also investigate the local characteristics of the network structure. The local analysis allows us to identify the main airports in Brazil and their roles in the overall operation of the air transportation network. 93.3\% of the airports have less than 40 connections. Just 8 airports have more than 40 connections. The airport with the most connections from/to is Viracopos in Campinas city (SBKP) with 105. It is clear that the network infrastructure follows a scale-free model, with some airports acting like hubs.

An interesting finding is that Viracopos Airport plays an important role in the national network infrastructure. This affirmation is corroborated by the top-20 most central airports, considering the 
TABLE VI

Top-20 Airports - Number of Connections - National Flights.

\begin{tabular}{c|c|c|c|c}
\hline Name (ICAO) & Connections & Passengers & Betweenness & PageRank \\
\hline Viracopos (SBKP) & 105 & 256,234 & 0.3 & 0.06 \\
\hline Guarulhos (SBGR) & 86 & 602,801 & 0.15 & 0.04 \\
\hline Brasília (SBBR) & 74 & 450,647 & 0.2 & 0.04 \\
\hline Confins (SBCF) & 59 & 280,340 & 0.09 & 0.03 \\
\hline Congonhas (SBSP) & 52 & 530,779 & 0.03 & 0.02 \\
\hline Galeão (SBGL) & 48 & 331,433 & 0.03 & 0.02 \\
\hline Salvador (SBSV) & 46 & 230,771 & 0.05 & 0.02 \\
\hline Porto Alegre (SBPA) & 41 & 197,394 & 0.08 & 0.02 \\
\hline Cuiabá (SBCY) & 38 & 81,963 & 0.08 & 0.02 \\
\hline Curitibá (SBCT) & 36 & 216,513 & 0.04 & 0.02 \\
\hline Manaus (SBEG) & 34 & 313,519 & 0.03 & 0.01 \\
\hline Santos Dumont (SBRJ) & 34 & 82,937 & 0.22 & 0.02 \\
\hline Belém (SBBE) & 30 & 177,179 & 0.01 & 0.01 \\
\hline Recife (SBRF) & 30 & 118,535 & 0.08 & 0.02 \\
\hline Fortaleza (SBFZ) & 28 & 163,117 & 0 & 0.01 \\
\hline Ribeirão Preto (SBRP) & 24 & 34,852 & 0 & 0.01 \\
\hline Goiânia (SBGO) & 23 & 91,689 & 0.01 & 0.01 \\
\hline Campo Grande (SBCG) & 22 & 45,563 & 0.01 & 0.01 \\
\hline Pampulha (SBBH) & 21 & 16,838 & 0.05 & 0.01 \\
\hline Vitória (SBVT) & 20 & 95,236 & 0 & 0.01 \\
\hline
\end{tabular}

main centrality measures, shown in Tables VI to IX (Airport label is its ICAO $^{9}$ code). Although Viracopos Airport does not hold the maximum number of passengers per week (Guarulhos Airport has the maximum number of passengers), it is the most frequent airport present in the shortest paths over the network (high betweenness centrality). Furthermore, considering the number of passengers and the airports that have at least one flight between them, Viracopos has also the highest PageRank centrality. We conjecture that Viracopos turns to one the most important Brazilian airports after the Azul Airline Company ${ }^{10}$ creation. Viracopos airport is the main company hub and a large number of routes pass through it, increasing a lot the importance of this airport in the national connections network.

Figure 1 shows a big picture of Brazilian airline network. The node size is proportional to its degree

\footnotetext{
${ }^{9}$ http://www.icao.int/Pages/default.aspx

${ }^{10} \mathrm{http}$ ://www.voeazul.com.br/
}

and the color to its betweenness centrality (red color means high betweenness centrality). Some interesting conclusions can be hold. The most important airports are not well spread over the Brazilian territory. The most connected airports are concentrated in the Southeast region. In some cases, people from North and Northeast regions need fly to some hub in the Southeast region in order to go back to some city in those regions. The only airport in North and Northeast region that plays an important role in Brazil airline infrastructure is Manaus Airport (SBEG). The majority of airports have few connections and are not placed into the shortest paths in the airline network (the blue ones). As expected, the most important airports are placed in the capital cities.

Edges in Figure 1 represent the total number of passengers between two airports and their thicknesses are proportional to the total number of passengers on the route. The total number of passengers between Congonhas and Santos Dumont Airports (148, 352 passengers per week) is twice the second busiest graph connection, i.e., Congonhas and Brasília Airports (60, 129 passengers per week). The route 
TABLE VII

Top-20 Airports - Maximum Number of Passengers - National Flights.

\begin{tabular}{c|c|c|c|c}
\hline Name (ICAO) & Passengers & Connections & Betweenness & PageRank \\
\hline Guarulhos (SBGR) & 602,801 & 86 & 0.15 & 0.04 \\
\hline Congonhas (SBSP) & 530,779 & 52 & 0.03 & 0.02 \\
\hline Brasília (SBBR) & 450,647 & 74 & 0.2 & 0.04 \\
\hline Galeão (SBGL) & 331,433 & 48 & 0.03 & 0.02 \\
\hline Santos Dumont (SBRJ) & 313,519 & 34 & 0.03 & 0.01 \\
\hline Confins (SBCF) & 280,340 & 59 & 0.09 & 0.03 \\
\hline Viracopos (SBKP) & 256,234 & 105 & 0.3 & 0.06 \\
\hline Salvador (SBSV) & 230,771 & 46 & 0.05 & 0.02 \\
\hline Curitiba (SBCT) & 216,513 & 36 & 0.04 & 0.02 \\
\hline Porto Alegre (SBPA) & 197,394 & 41 & 0.08 & 0.02 \\
\hline Recife (SBRF) & 177,179 & 30 & 0.01 & 0.01 \\
\hline Fortaleza (SBFZ) & 163,117 & 28 & 0 & 0.01 \\
\hline Belém (SBBE) & 118,535 & 30 & 0.08 & 0.02 \\
\hline Florianópolis (SBFL) & 99,775 & 14 & 0 & 0 \\
\hline Vitória (SBVT) & 95,236 & 20 & 0 & 0.01 \\
\hline Goiânia (SBGO) & 91,689 & 23 & 0.01 & 0.01 \\
\hline Manaus (SBEG) & 82,937 & 34 & 0.22 & 0.02 \\
\hline Cuiabá (SBCY) & 81,963 & 38 & 0.08 & 0.02 \\
\hline Natal (SBNT) & 59,680 & 17 & 0 & 0 \\
\hline São Luís (SBSL) & 58,170 & 16 & 0 & 0
\end{tabular}

TABLE VIII

Top-20 Airports - Betweenness

Centrality - National Flights.

\begin{tabular}{c|c|c|c|c}
\hline Name (ICAO) & Betweenness & Connections & Passengers & PageRank \\
\hline Viracopos (SBKP) & 0.30 & 105 & 256,234 & 0.06 \\
\hline Manaus (SBEG) & 0.22 & 34 & 82,937 & 0.02 \\
\hline Brasília (SBBR) & 0.20 & 74 & 450,647 & 0.04 \\
\hline Guarulhos (SBGR) & 0.15 & 86 & 602,801 & 0.04 \\
\hline Confins (SBCF) & 0.09 & 59 & 280,340 & 0.03 \\
\hline Belém (SBBE) & 0.08 & 30 & 118,535 & 0.02 \\
\hline Cuiabá (SBCY) & 0.08 & 38 & 81,963 & 0.02 \\
\hline Tefé (SBTF) & 0.08 & 14 & 3,523 & 0.02 \\
\hline Porto Alegre (SBPA) & 0.08 & 41 & 197,394 & 0.02 \\
\hline Palmas (SBPJ) & 0.05 & 12 & 18,714 & 0.01 \\
\hline Salvador (SBSV) & 0.05 & 46 & 230,771 & 0.02 \\
\hline Pampulha (SBBH) & 0.05 & 21 & 16,838 & 0.01 \\
\hline Curitiba (SBCT) & 0.04 & 36 & 216,513 & 0.02 \\
\hline Santos Dumont (SBRJ) & 0.03 & 34 & 313,519 & 0.01 \\
\hline Santarém (SBSN) & 0.03 & 10 & 25,352 & 0.01 \\
\hline Congonhas (SBSP) & 0.03 & 52 & 530,779 & 0.02 \\
\hline Galeão (SBGL) & 0.03 & 48 & 331,433 & 0.02 \\
\hline Marabá (SBMA) & 0.02 & 14 & 18,286 & 0.01 \\
\hline Campo Grande (SBCG) & 0.01 & 22 & 45,563 & 0.01 \\
\hline Goiânia (SBGO) & 0.01 & 23 & 91,689 & 0.01 \\
\hline
\end{tabular}




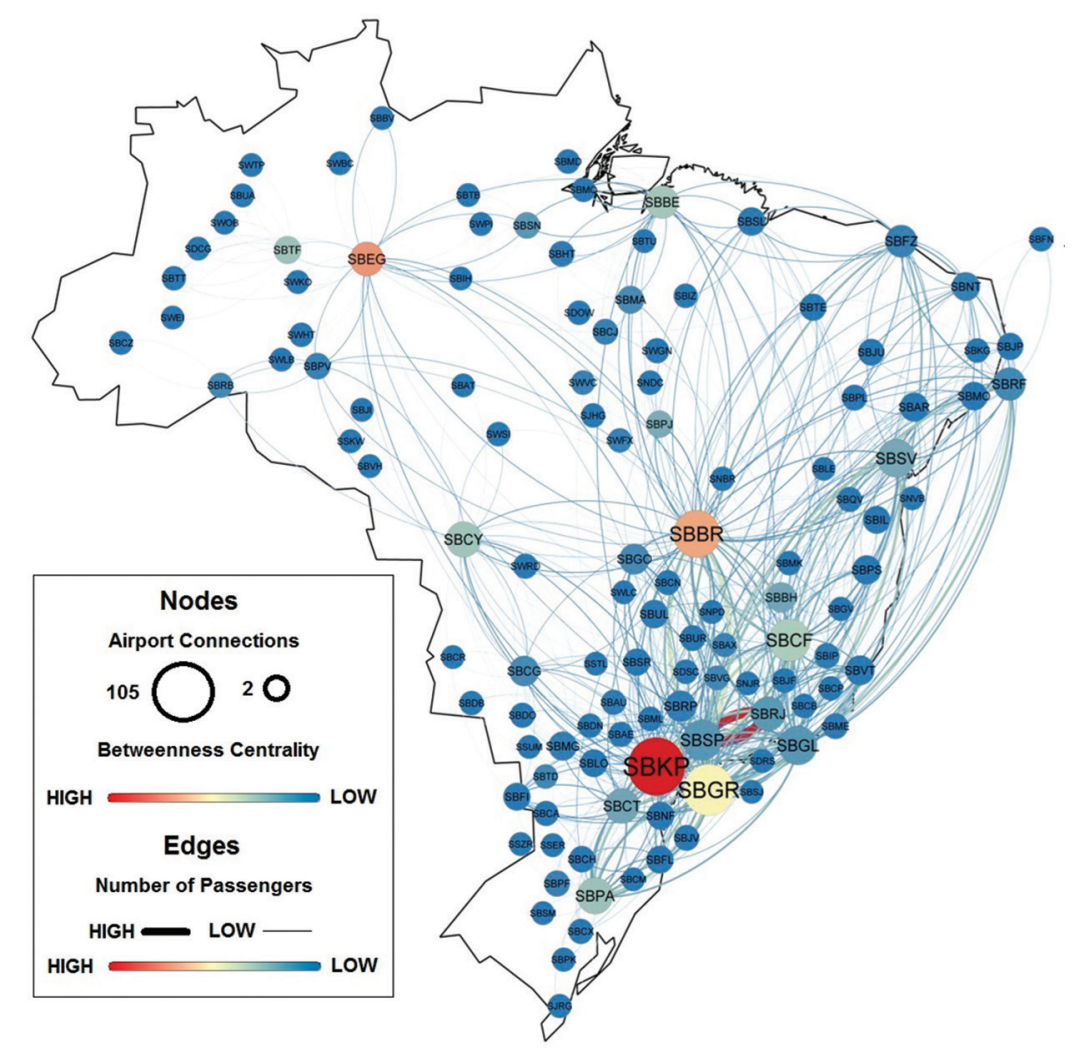

Figure 1 - Central Brazilian Airports - National Flights. For interpretation of the references to color in this figure, the reader is referred to the web version of this article.

Congonhas - Santos Dumont Airports concentrates a huge amount of passengers given that São Paulo and Rio de Janeiro are the most important cities in Brazil, both in terms of number of population and economic power.

Tables X and XI show the 20 airports with the highest and the lowest closeness centrality values, respectively. Airports with the highest closeness values are placed in the main Brazilian cities (capitals in Southeast, South and coastal region). Airports with the lowest closeness values are place in the North, Northeast Brazilian regions as well as in small cities.

\section{Community structure}

Most of real networks show community structure, i.e., groups of nodes that have a high density of links among them, with a lower density of links between different groups. Communities can be build following some rules based on specific characteristics related to the entities that formed them. The understanding of community existence as well as the pattern formation is one of many important tasks in network science theory (Iñiguez et al. 2009, Newman 2006, Fortunato 2010). In terms of air transportation networks, the community formation phenomena may shed light on, whether, if the community formation follows the geographical country division.

We verify if Brazilian airports are grouped into different communities. We performed the algorithm proposed by (Blondel et al. 2008). Communities are defined based on the airports connections. In this sense, airports in the same community have many more connections with each other inside the community than with airports outside of the community. Figure 2 shows the community structure of the network. Each color represents a 
TABLE IX

Top-20 Airports - PageRank

Centrality - National Flights.

\begin{tabular}{c|c|c|c|c}
\hline Name (ICAO) & PageRank & Connections & Passengers & Betweenness \\
\hline Viracopos (SBKP) & 0.06 & 105 & 256,234 & 0.30 \\
\hline Guarulhos (SBGR) & 0.04 & 86 & 602,801 & 0.15 \\
\hline Brasília (SBBR) & 0.04 & 74 & 450,647 & 0.20 \\
\hline Confins (SBCF) & 0.03 & 59 & 280,340 & 0.09 \\
\hline Manaus (SBEG) & 0.02 & 34 & 82,937 & 0.22 \\
\hline Congonhas (SBSP) & 0.02 & 52 & 530,779 & 0.03 \\
\hline Salvador (SBSV) & 0.02 & 46 & 230,771 & 0.05 \\
\hline Porto Alegre (SBPA) & 0.02 & 41 & 197,394 & 0.08 \\
\hline Galeão (SBGL) & 0.02 & 48 & 331,433 & 0.03 \\
\hline Cuiabá (SBCY) & 0.02 & 38 & 81,963 & 0.08 \\
\hline Tefé (SBTF) & 0.02 & 14 & 3,523 & 0.08 \\
\hline Belém (SBBE) & 0.02 & 30 & 118,535 & 0.08 \\
\hline Curitiba (SBCT) & 0.02 & 36 & 216,513 & 0.04 \\
\hline Santos Dumont (SBRJ) & 0.01 & 34 & 313,519 & 0.03 \\
\hline Pampulha (SBBH) & 0.01 & 21 & 16,838 & 0.05 \\
\hline Recife (SBRF) & 0.01 & 30 & 177,179 & 0.01 \\
\hline Fortaleza (SBFZ) & 0.01 & 28 & 163,117 & 0.01 \\
\hline Goiânia (SBGO) & 0.01 & 23 & 91,689 & 0.01 \\
\hline Ribeirão Preto (SBRP) & 0.01 & 24 & 34,852 & 0.00 \\
\hline Campo Grande (SBCG) & 0.01 & 22 & 45,563 & 0.01 \\
\hline
\end{tabular}

community found by the algorithm. Interestingly, the communities structure almost reflects the Brazilian regions. North (Amazonia) region has the Manaus Airport (SBEG) as the major one. We also have a smaller group (pink one) that represents some airports of sates of Tocantins, Pará and Mato Grosso, such as Marabá Airport (SBMA) and Palmas Airport (SBPJ) each with less than 19,000 passengers per week. The remaining airports are small ones with less than 4,000 passengers per week.

The green community is very similar, geographically speaking, to the Northeast Brazilian region. However, this community also includes Brasília, Confins and Galeão airports, meaning that the Northeast region is highly dependant on the South Airports. The dark blue community is composed by small airports, mainly from the state of Minas Gerais. The light blue community has Viracopos Airport, the most connected airport considering national flight connections. Furthermore, it englobes many airports from the Southeast region. The yellow
TABLE X

Top-20 Airports - Highest Closeness Centrality - National Flights.

\begin{tabular}{c|c|c}
\hline Name (ICAO) & $\begin{array}{c}\text { Closeness(Average } \\
\text { Shortest Path) }\end{array}$ & Connections \\
\hline Viracopos (SBKP) & $0.58(1.7)$ & 105 \\
\hline Brasília (SBBR) & $0.55(1.8)$ & 74 \\
\hline Guarulhos (SBGR) & $0.54(1.84)$ & 86 \\
\hline Confins (SBCF) & $0.52(1.91)$ & 59 \\
\hline Galeão (SBGL) & $0.5(1.98)$ & 48 \\
\hline Manaus (SBEG) & $0.46(2.13)$ & 34 \\
\hline Belém (SBBE) & $0.45(2.17)$ & 30 \\
\hline Fortaleza (SBFZ) & $0.45(2.18)$ & 28 \\
\hline Congonhas (SBSP) & $0.45(2.2)$ & 52 \\
\hline Curitiba (SBCT) & $0.45(2.21)$ & 36 \\
\hline Salvador (SBSV) & $0.44(2.22)$ & 46 \\
\hline Porto Alegre (SBPA) & $0.44(2.22)$ & 41 \\
\hline Santos Dumont (SBRJ) & $0.44(2.24)$ & 34 \\
\hline Cuiabá (SBCY) & $0.44(2.26)$ & 38 \\
\hline Goiânia (SBGO) & $0.43(2.3)$ & 23 \\
\hline Recife (SBRF) & $0.42(2.33)$ & 30 \\
\hline Ribeirão Preto (SBRP) & $0.42(2.35)$ & 24 \\
\hline Campo Grande (SBCG) & $0.42(2.35)$ & 22 \\
\hline Vitria (SBVT) & $0.42(2.36)$ & 20 \\
\hline Aracaju (SBAR) & $0.42(2.36)$ & 18 \\
\hline & &
\end{tabular}


community is composed by airports from the South region as well as by the Guarulhos and Congonhas airports. The community analysis provides a nice way of identifying airports dependencies from both structural and economic points of view. Moreover, it is also possible to have some insights of air company's economics interests.

\section{Resiliency analysis}

Resiliency analysis gives important insights on the airline network robustness under topology changes. For instance, some airports can be closed as a consequence of bad weather conditions or operational problems. Consequently, routes have to be redefined. Here, we study the impact on the number of components as well as on the total number of passengers when some airports are removed from the network.

Our resiliency analysis proceeds as follows. We perform airports removals targeting the most central nodes in the network, according to the number of connections, betweenness and number of passengers. We remove nodes in decreasing order

\section{TABLE XI}

The 20 airports with the lowest closeness centrality values.

\begin{tabular}{c|c|c}
\hline Name (ICAO) & Closeness & Connections \\
\hline Confresa (SJHG) & $0.21(4.65)$ & 4 \\
\hline Umuarama (SSUM) & $0.23(4.17)$ & 2 \\
\hline Tapuruquara (SWTP) & $0.24(4.02)$ & 2 \\
\hline São Paulo de Olivença (SDCG) & $0.24(4.02)$ & 2 \\
\hline Fonte Boa (SWOB) & $0.24(4.02)$ & 2 \\
\hline Eirunepé (SWEI) & $0.24(4.02)$ & 2 \\
\hline Uaupés (SBUA) & $0.24(4.02)$ & 2 \\
\hline Porto Trombetas (SBTB) & $0.25(3.99)$ & 2 \\
\hline Itaituba (SBIH) & $0.25(3.99)$ & 2 \\
\hline Cruzeiro do Sul (SBCZ) & $0.26(3.75)$ & 2 \\
\hline Vila Rica (SWVC) & $0.27(3.68)$ & 4 \\
\hline São Félix do Araguaia (SWFX) & $0.27(3.68)$ & 4 \\
\hline São João del-Rei (SNJR) & $0.27(3.66)$ & 2 \\
\hline Ourilândia do Norte (SDOW) & $0.27(3.57)$ & 4 \\
\hline Redenção (SNDC) & $0.27(3.57)$ & 4 \\
\hline Erechim (SSER) & $0.28(3.55)$ & 2 \\
\hline Governador Valadares (SBGV) & $0.28(3.51)$ & 3 \\
\hline Patos de Minas (SNPD) & $0.28(3.50)$ & 2 \\
\hline Araxá (SBAX) & $0.28(3.49)$ & 3 \\
\hline Corumbá (SBCR) & $0.29(3.34)$ & 2 \\
\hline
\end{tabular}

of their metric values. Consecutive removals are performed until the giant component achieves half of its initial size.

Figures 3 and 4 show the results. Considering the number of components, the worst case happens when airports with the highest betweenness measures are removed from the network. By removing the three airports with the highest betweenness (Viracopos, Guarullhos and Brasília in this order), the network is fragmented into 6 connected components. Considering the percentage of the passengers, the worst case occurs by removing four airports (Guarulhos, Congonhas, Brasília and Galeão Airports in this order). The total number of passengers drops to almost $30 \%$ of the total capacity.

This analysis shows how dangerous it is to remove an airport in the network. For instance, let us consider the Viracopos airport (SBKP). It is the most important airport considering national connections, in terms of topological characteristics. As expected, its removal can cause many disconnection points. Table I shows that Viracopos airport is equipped with ILS CAT I which is not suitable for dealing with extreme weather conditions. Then, Viracopos airport has high chances of being closed due to bad weather conditions. This fact influences the network topology stability.

\section{Time analysis}

The results in the previous sections do not take into account any information about flight duration and flight daily distribution. To investigate the time impact in our analysis, we included the flight duration in each edge of our graph model. Including time in our analysis allows to obtain some interesting results.

Figure 5 shows the air transportation network where nodes are proportional to the time flights among airports: nodes with largers size represent airports with greater average flight durations from them. The largest one-hop flight departs from Galeão Airport (SBGL) and arrives at 


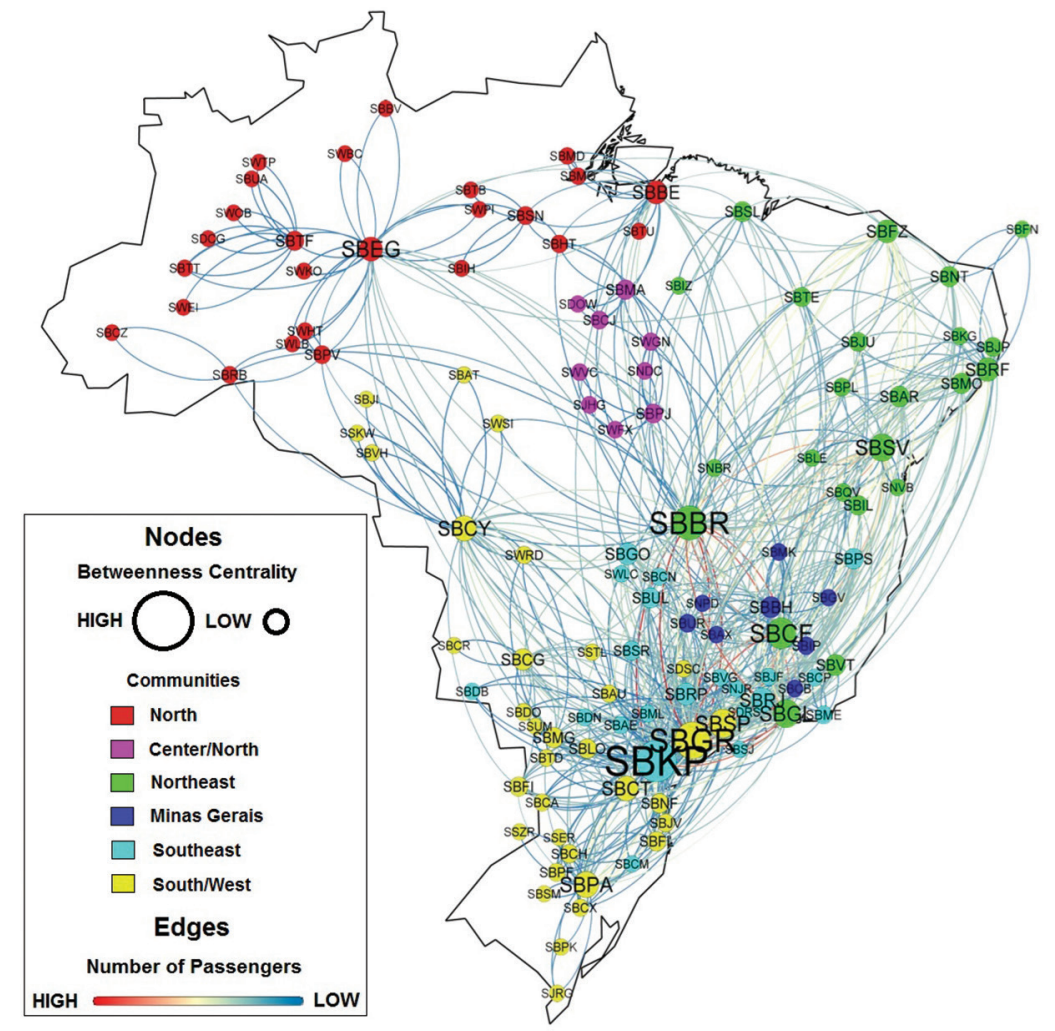

Figure 2 - Airports grouped by different communities. For interpretation of the references to color in this figure, the reader is referred to the web version of this article.

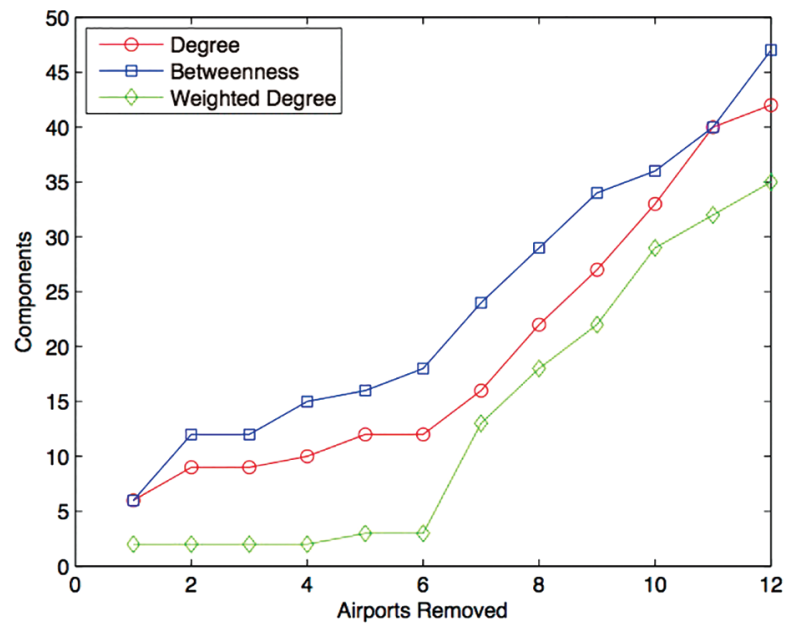

Figure 3 - Changes to the number of components by the total number of removed airports. For interpretation of the references to color in this figure, the reader is referred to the web version of this article.

Manaus Airport (SBEG) with duration of 245 minutes. The smallest one-hop flight departs from Ipatinga Airport (SBIP) and arrives at Governador

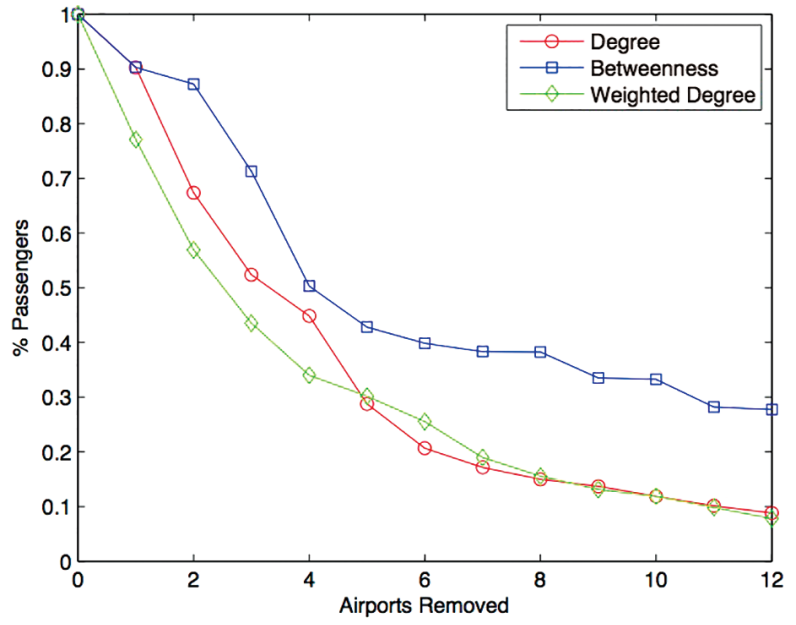

Figure 4 - Changes to the percentage of passengers by the total number of removed airports. For interpretation of the references to color in this figure, the reader is referred to the web version of this article.

Valadares Airport (SBGV) with duration of 15 minutes. The results corroborate the metrics previously calculated. 
Tables XII and XIII show the airports with the largest and smallest average path durations (in minutes) to all airports in the Brazilian air transportation network. We calculate all pairs of shortest paths considering flight duration. It is worth noting that we are not taking into account the time spent between connections. We compute the average time for traveling from one airport to the all anothers in the network. Tables XII and XIII also show the longest travel time calculated from all-to-all paths.
Lastly, we briefly discuss how the interruption in the airports' activities, in terms of time duration and period of day, impacts the Brazilian air transportation network robustness. Section 4.2.2 (See Resiliency Analysis) shows that Viracopos, Guarulhos, Brasília, Congonhas and Galeão Airports are the most important airports when we focus on network robustness. Figure 6 shows the daily flight distribution. Flights in Viracopos, Brasília and Galeão have two peak intervals of

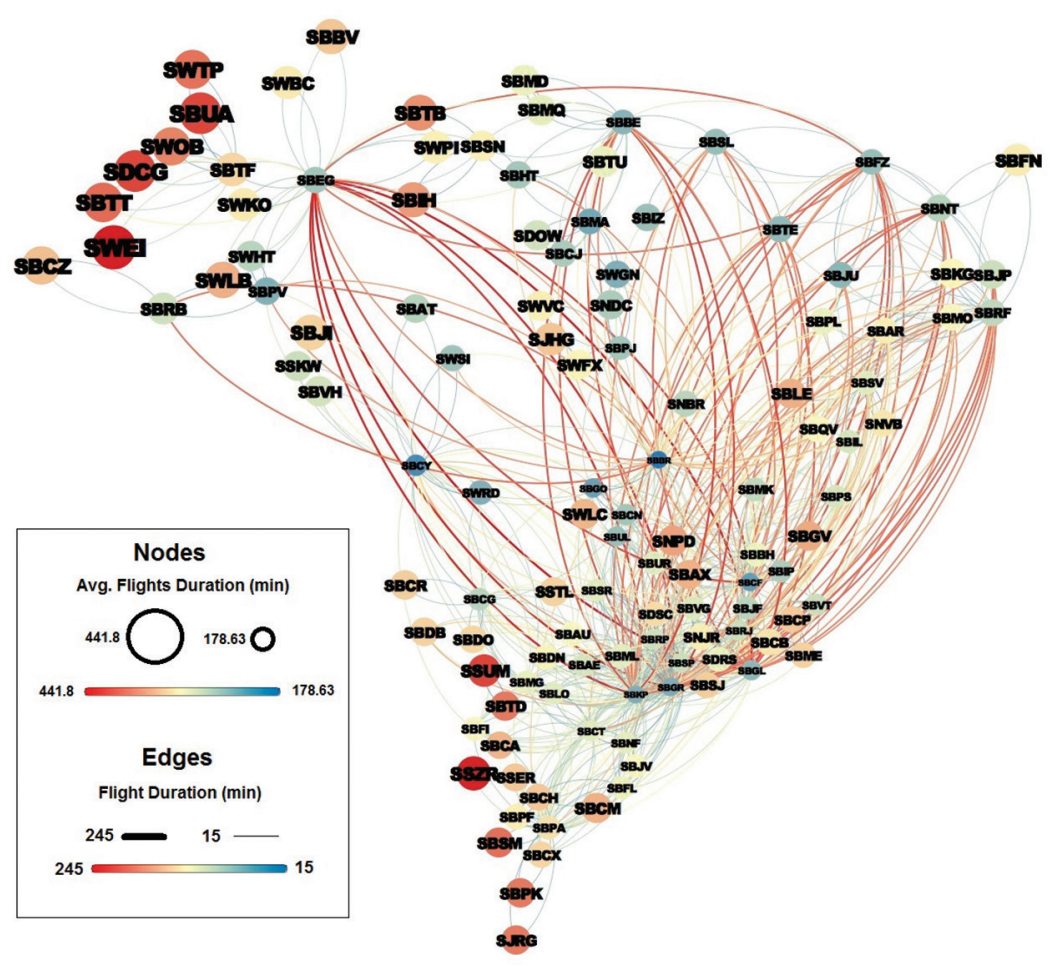

Figure 5 - Brazilian airports and their flights duration representation. For interpretation of the references to color in this figure, the reader is referred to the web version of this article.

flight concentration: [6AM, 10AM] and [6PM and 10PM]. The interruption of the activities during these intervals severely impacts all network, due to the fact that these airports connect several other airports between themselves. Guarulhos and Congonhas have a smoother distribution during the day, resulting in a worse scenario for the interruption of the activities. The worst consequence in the network functioning is the severe cascade delay effect on all flights in the network.

INTERNATIONAL NETWORK CHARACTERISTICS

In order to understand how international flights are organized in the airline network, we built a graph composed of the Brazilian airports that support international flights and the international airports 
TABLE XII

Top-20 largest average time of all paths in the air transportation network.

\begin{tabular}{c|c|c}
\hline ICAO & Average Travel Time (min) & Longest Travel Time (min) \\
\hline SWEI & 441.8 & 617 \\
\hline SBUA & 417.01 & 592 \\
\hline SDCG & 417.01 & 592 \\
\hline SBTT & 396.54 & 570 \\
\hline SWTP & 392.22 & 567 \\
\hline SBCZ & 384.72 & 525 \\
\hline SWOB & 382.31 & 557 \\
\hline SWLB & 365.75 & 533 \\
\hline SBTB & 358.54 & 551 \\
\hline SBJI & 355.9 & 513 \\
\hline SBBV & 353.79 & 521 \\
\hline SBIH & 352.52 & 545 \\
\hline SSZR & 343.63 & 611 \\
\hline SBTF & 337.68 & 512 \\
\hline SWKO & 334.06 & 501 \\
\hline SWBC & 333.96 & 501 \\
\hline SWPI & 331 & 498 \\
\hline SJHG & 326.54 & 521 \\
\hline SBFN & 326.3 & 501 \\
\hline SSUM & 325.99 & 593 \\
\hline & &
\end{tabular}

that have flights to Brazil. Graph $\mathcal{G}_{\text {international }}$ has 68 airports, 15 of them in Brazil and 53 of them overseas.

Different from the national view, the generated graph has two components. One englobes Belém (SBBE), Surinam and French Guiana airports. The other component is the giant strongly connected component covering all other Brazilian and foreign airports. The main global metrics are summarized in Table XIV on average, every international Brazilian airport has connections to 3 other foreign airports. Approximately 7, 208 passengers travel per airport in a week.

Figure 7 shows the two main graph components. Furthermore, node size is proportional to the connections to a given airport: Guarulhos Airport (SBGR) plays the most important role in the airline international network, followed by the Galeão Airport (SBGL). Table XV shows the total number of international passengers supported by each airport. Guarulhos and Galeão Airports hold, respectively, 313,275 and 100,886 passengers per week ( $84 \%$ of the international passengers). This result reinforces the importance
TABLE XIII

Top-20 smallest average time of all paths in the air transportation network.

\begin{tabular}{c|c|c}
\hline Name (ICAO) & $\begin{array}{c}\text { Average Travel } \\
\text { Time (min) }\end{array}$ & $\begin{array}{c}\text { Longest Travel } \\
\text { Time (min) }\end{array}$ \\
\hline Brasília (SBBR) & 178.63 & 355 \\
\hline Viracopos (SBKP) & 182.16 & 409 \\
\hline Confins (SBCF) & 185.23 & 391 \\
\hline Guarulhos (SBGR) & 190.21 & 408 \\
\hline Goiânia (SBGO) & 197 & 395 \\
\hline Congonhas (SBSP) & 199.71 & 458 \\
\hline Galeão (SBGL) & 203.86 & 417 \\
\hline Uberlândia (SBUL) & 204.05 & 425 \\
\hline Santos Dumont (SBRJ) & 206.52 & 458 \\
\hline Curitiba (SBCT) & 208.51 & 473 \\
\hline Ribeirão Preto (SBRP) & 210.56 & 460 \\
\hline Cuiabá (SBCY) & 217.06 & 373 \\
\hline Caldas Novas (SBCN) & 217.86 & 432 \\
\hline Vitória (SBVT) & 222.09 & 457 \\
\hline Navegantes (SBNF) & 222.77 & 474 \\
\hline Londrina (SBLO) & 224.28 & 472 \\
\hline São José R.P (SBSR) & 224.34 & 473 \\
\hline Campo Grande (SBCG) & 227.66 & 446 \\
\hline Ipatinga (SBIP) & 227.75 & 439 \\
\hline Porto Seguro (SBPS) & 229.91 & 466 \\
\hline & &
\end{tabular}


TABLE XIV

International Connections.

\begin{tabular}{c|c}
\hline Metric & Value \\
\hline Connected Components & $2(68$ airports $)$ \\
\hline Average Connections & 3.265 \\
\hline Average Weighted Degree & 7,208 \\
\hline Diameter & 6 \\
\hline Average Shortest Path & 2.389 \\
\hline Graph Density & 0.049 \\
\hline
\end{tabular}

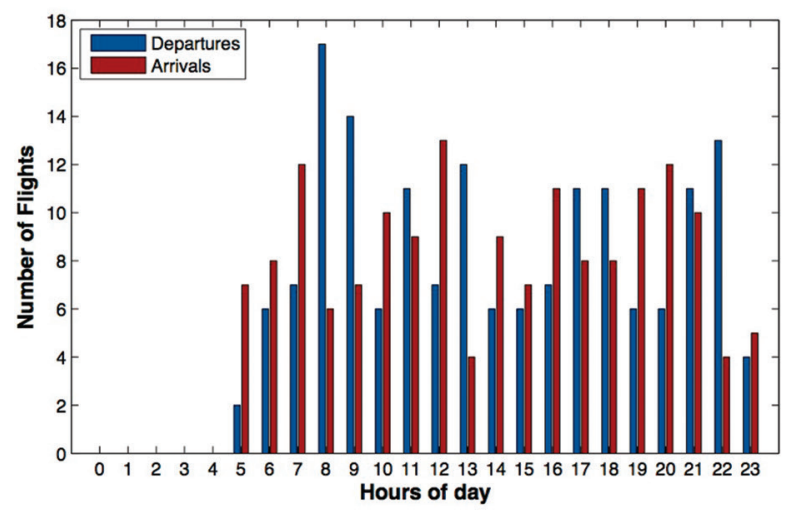

(a) Viracopos Airport

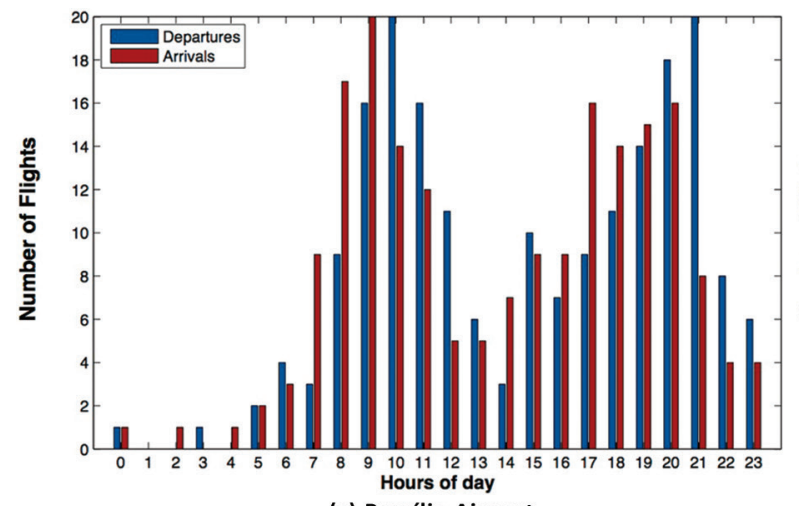

(c) Brasília Airport of Guarulhos and Galeão airports and the need for efficient contingency policies in both airports.

Figure 8 shows that Brazil has three main overseas connections: Miami (KMIA), Buenos Aires (SAEZ) and Lisboa Airports (LPPT). Airports in Brazil are the main en trances/exits to/from South America of people coming to/from North America

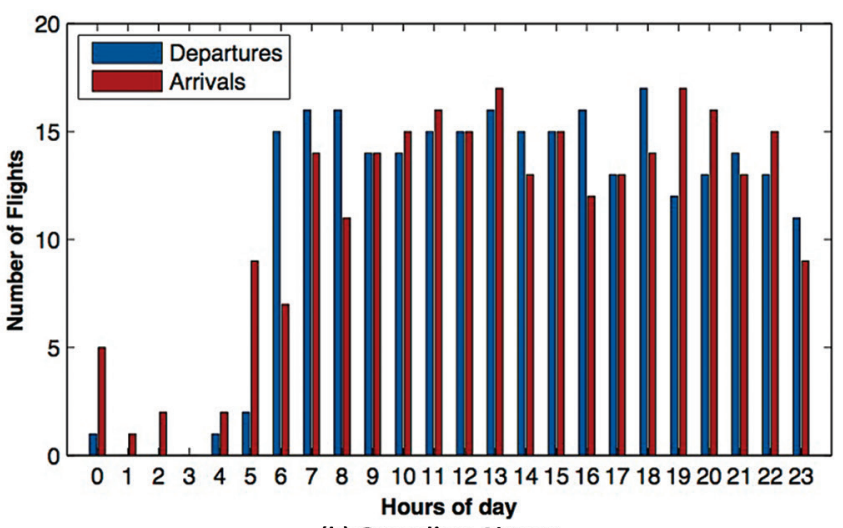

(b) Guarulhos Airport

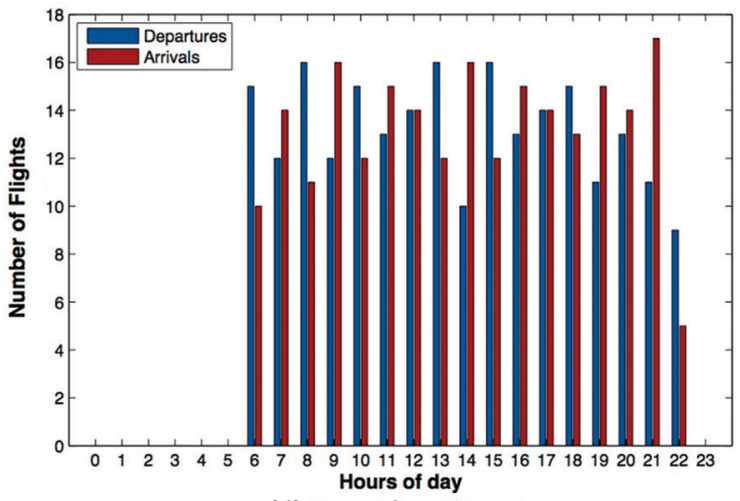

(d) Congonhas Airport

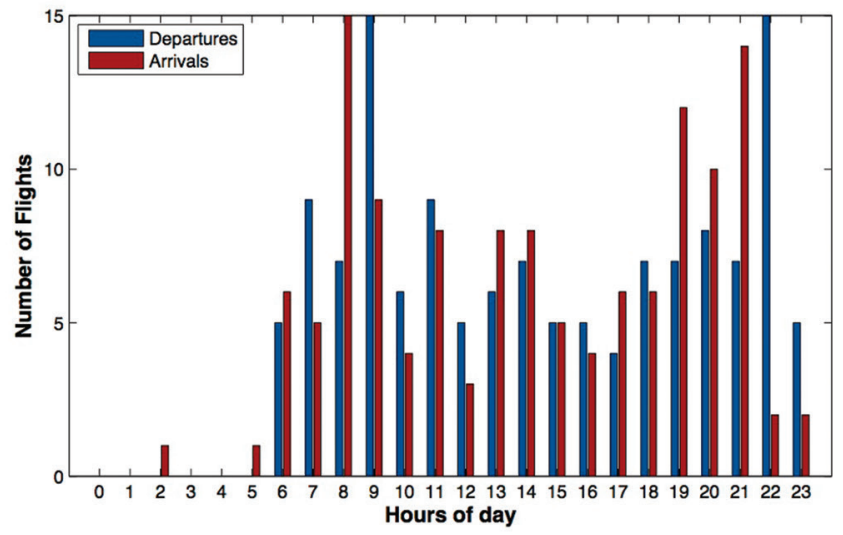

(e) Galeão Airport

Figure 6 - Daily distribution of flights. For interpretation of the references to color in this figure, the reader is referred to the web version of this article. 
TABLE XV

Top-20 - Maximum Number of

Passengers - International Flights.

\begin{tabular}{c|c|c|c|c}
\hline Name (ICAO) & Passengers & Connections & Passengers (in) & Passengers (out) \\
\hline Guarulhos (SBGR) & 313,275 & 96 & 156,774 & 156,501 \\
\hline Galeão (SBGL) & 100,886 & 50 & 50,443 & 50,443 \\
\hline Ezeiza (SAEZ) & 52,260 & 16 & 26,130 & 26,130 \\
\hline Miami (KMIA) & 44,824 & 14 & 22,412 & 22,412 \\
\hline Lisbon (LPPT) & 36,868 & 20 & 18,434 & 18,434 \\
\hline Santiago (SCEL) & 26,714 & 4 & 13,357 & 13,357 \\
\hline Jorge Newbery (SABE) & 25,270 & 6 & 12,635 & 12,635 \\
\hline John F. Kennedy (KJFK) & 22,892 & 4 & 11,446 & 11,446 \\
\hline Tocumen (MPTO) & 21,964 & 14 & 10,982 & 10,982 \\
\hline Charles de Gaulle (LFPG) & 19,366 & 4 & 9,683 & 9,683 \\
\hline Madrid-Barajas (LEMD) & 18,544 & 6 & 9,272 & 9,272 \\
\hline Carrasco (SUMU) & 15,501 & 6 & 7,614 & 7,887 \\
\hline Frankfurt (EDDF) & 15,088 & 8 & 7,544 & 7,544 \\
\hline London Heathrow (EGLL) & 14,472 & 4 & 7,236 & 7,236 \\
\hline Jorge Chvez (SPIM) & 13,882 & 8 & 6,941 & 6,941 \\
\hline Porto Alegre (SBPA) & 13,702 & 12 & 6,851 & 6,851 \\
\hline Brasília (SBBR) & 13,662 & 10 & 6,831 & 6,831 \\
\hline El Dorado (SKBO) & 9,982 & 4 & 4,991 & 4,991 \\
\hline Confins (SBCF) & 9,838 & 8 & 4,919 & 4,919 \\
\hline
\end{tabular}

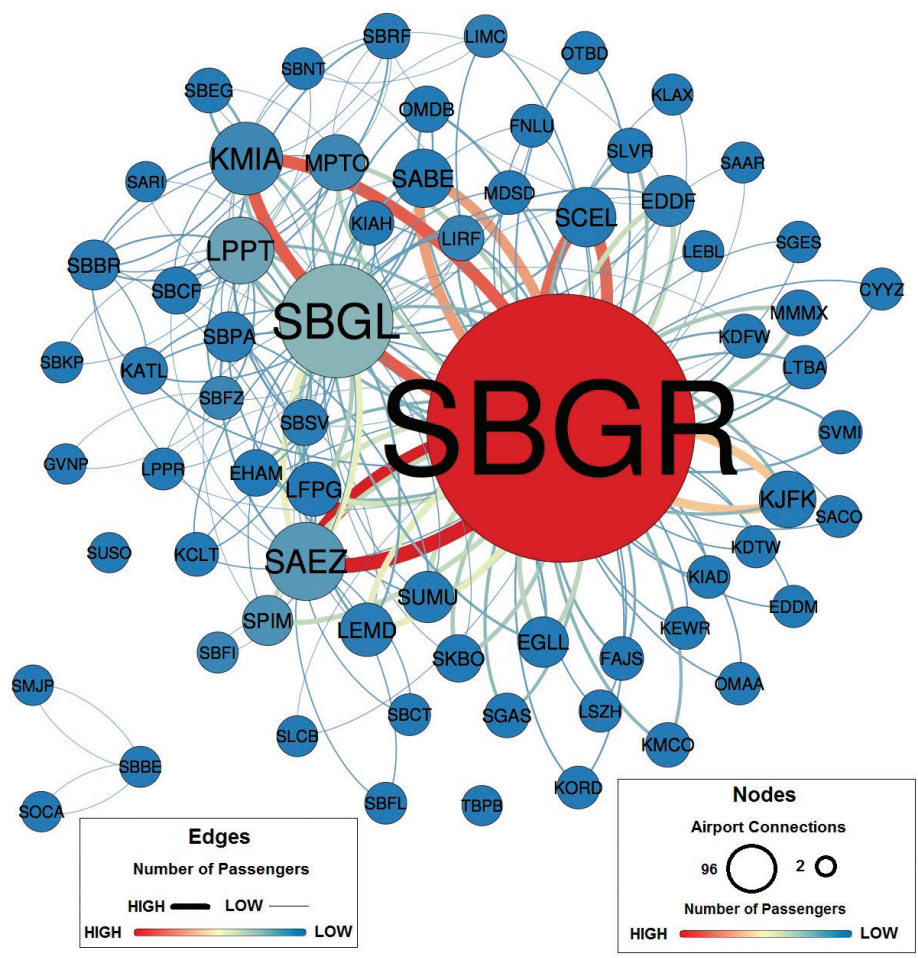

Figure 7 - Network - International Flights. For interpretation of the references to color in this figure, the reader is referred to the web version of this article. 


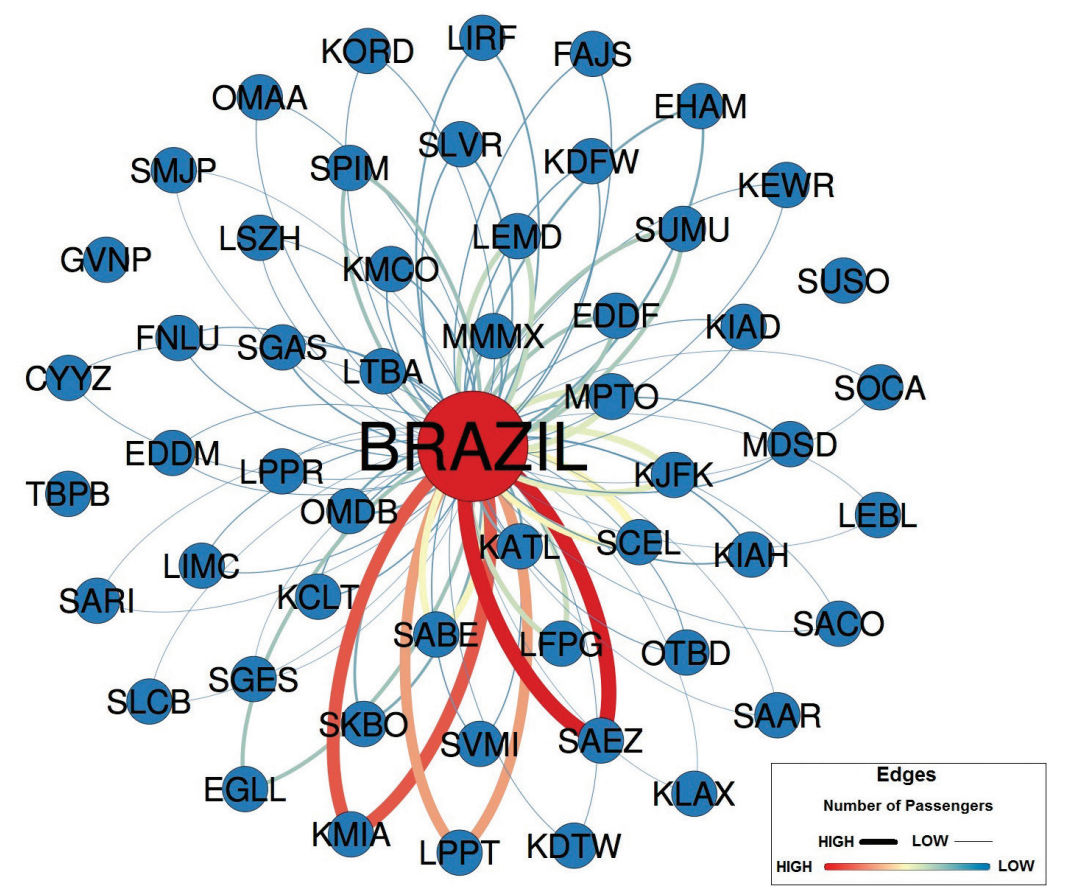

Figure 8 - Brazilian Connections from/to Worldwide. For interpretation of the references to color in this figure, the reader is referred to the web version of this article.

and Europe. Considering the current flights, the maximum number of passengers that are allowed to come to Brazil and to exit from Brazil are 245,232 and 244,959 passengers per week, respectively.

In this section, our analysis considers the national and international connections from/to Brazilian airports. $\mathcal{G}_{\text {overall }}$ graph has one component and, in the average, each airport connects to another 5.48 airports. Graph density is low, meaning that the connec tions are too sparse. On average, the

TABLE XVI

National and International Connections.

\begin{tabular}{c|c}
\hline Metric & Value \\
\hline Connected Components & $1(173$ airports $)$ \\
\hline Average Connections & $5.48(3.16 \%)$ \\
\hline Average Weighted Degree & 18,046 \\
\hline Diameter & 7 \\
\hline Average Shortest Path & 2.76 \\
\hline Graph Density & 0.03 \\
\hline Average Clustering Coefficient & 0.44 \\
\hline Average Neighborhood Overlap & 0.12 \\
\hline
\end{tabular}

total number of passengers is equal to 18,046 . The average trip size is equal to 2.76 . Table XVI summarizes the results.

Considering both national and international connections, Guarulhos and Viracopos are the most central airports in Brazil, as expected. Guarulhos plays a key role in airline network, dealing with the largest number of passengers and flights. Table XVII shows the main centrality measures, considering the top-20 Brazilian airports for the number of connections. As expected, the most connected airports are the state capitals ones and all of them have high closeness centrality.

\section{Resiliency analysis}

In this section we briefly discuss the resiliency of the international network. Our analysis proceed very similarly to the discussion in Section 4.2.2. (See Resiliency Analysis) As for the national network, we perform airports removals targeting the most central nodes in the network, according to the number of connections, betweenness and number of 
TABLE XVII

Top-20 Brazilian Airports - Number of Connections National and International Flights.

\begin{tabular}{c|c|c|c|c|c}
\hline Name (ICAO) & Connections & Passengers & Closeness & Betweenness & PageRank \\
\hline Guarulhos (SBGR) & 182 & 916,076 & 0.61 & 0.44 & 0.095 \\
\hline Viracopos (SBKP) & 107 & 257,812 & 0.51 & 0.18 & 0.048 \\
\hline Galeão (SBGL) & 98 & 432,319 & 0.54 & 0.1 & 0.044 \\
\hline Brasília (SBBR) & 84 & 464,309 & 0.54 & 0.14 & 0.035 \\
\hline Confins (SBCF) & 67 & 290,178 & 0.51 & 0.05 & 0.028 \\
\hline Salvador (SBSV) & 56 & 239,251 & 0.46 & 0.04 & 0.023 \\
\hline Porto Alegre (SBPA) & 53 & 211,096 & 0.46 & 0.06 & 0.024 \\
\hline Congonhas (SBSP) & 52 & 530,779 & 0.43 & 0.02 & 0.021 \\
\hline Recife (SBRF) & 38 & 184,673 & 0.44 & 0.01 & 0.015 \\
\hline Cuiabá (SBCY) & 38 & 81,963 & 0.45 & 0.05 & 0.019 \\
\hline Curitiba (SBCT) & 38 & 219,075 & 0.46 & 0.03 & 0.016 \\
\hline Manaus (SBEG) & 38 & 89,475 & 0.47 & 0.16 & 0.022 \\
\hline Santos Dumont (SBRJ) & 34 & 313,519 & 0.45 & 0.02 & 0.014 \\
\hline Belém (SBBE) & 34 & 119,883 & 0.47 & 0.08 & 0.018 \\
\hline Fortaleza (SBFZ) & 34 & 167,800 & 0.47 & 0.01 & 0.014 \\
\hline Ribeirão Preto (SBRP) & 24 & 34,852 & 0.44 & 0 & 0.01 \\
\hline Goiânia (SBGO) & 23 & 91,689 & 0.44 & 0.01 & 0.01 \\
\hline Campo Grande (SBCG) & 22 & 45,563 & 0.44 & 0.01 & 0.01 \\
\hline Pampulha (SBBH) & 21 & 16,838 & 0.41 & 0.03 & 0.012 \\
\hline Natal (SBNT) & 21 & 61,839 & 0.43 & 0 & 0.008 \\
\hline
\end{tabular}

passengers. Furthermore, we only remove Brazilian Airports. Figures 9 and 10 show the results.

From this simple analysis, it is possible to corroborate the importance of Guarulhos and

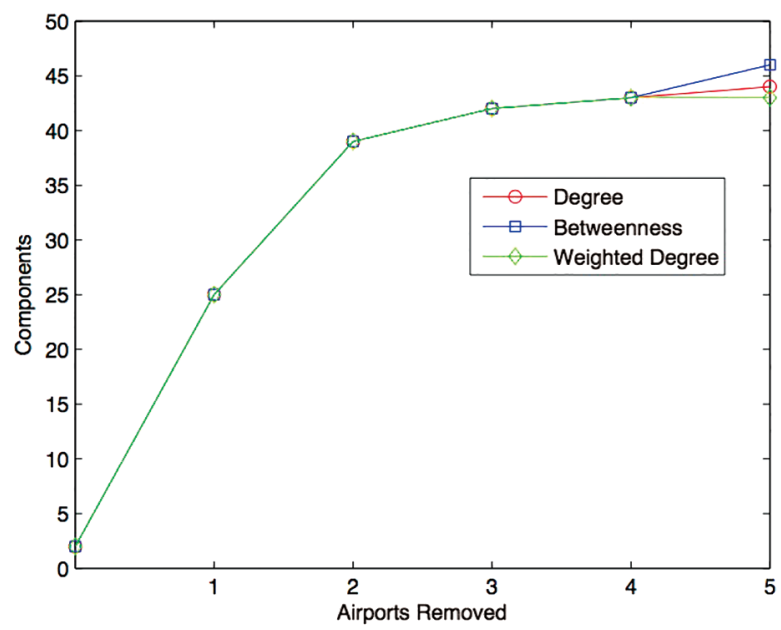

Figure 9 - Changes on the number of components by the total number of removed airports. For interpretation of the references to color in this figure, the reader is referred to the web version of this article.
Galeão Airports as exit point from Brazil to other countries. For all centrality metrics analyzed, both airports were removed in the first and second places. For the cases which Guarulhos Airport is

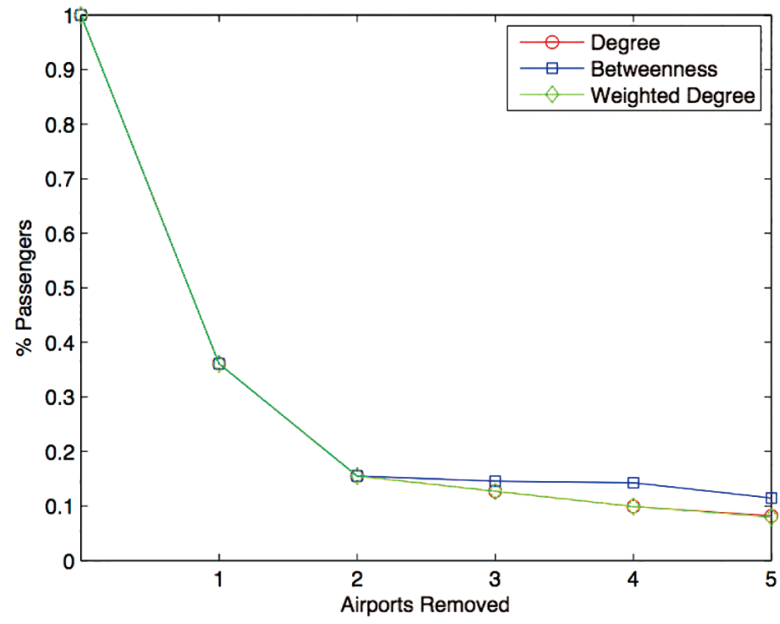

Figure 10 - Changes on the percentage of passengers by the total number of removed airports. For interpretation of the references to color in this figure, the reader is referred to the web version of this article. 
removed from the network, only $36 \%$ of passengers are allowed to travel abroad. Putting together the Galeão Airport, this number drops to $15 \%$. A similar impact can also be seen on the increase of the number of components in the network.

\section{CONCLUSIONS}

In this paper we analyzed the main topological characteristics of the Brazilian air transportation network, based on the set of national and international flights operated by the Brazilian airports.

The Brazilian network has small world properties and the airport connections follow a power law distribution. Our results showed that the main airports in the Brazilian infrastructure are the Viracopos and Guarulhos airports. Furthermore, travelers need, on average, 3 connection flights to reach their destinations. We also performed the resiliency analysis of the network robustness under topology changes. We showed that the Viracopos Airport outage breaks the network into 6 subnetworks, affecting $10 \%$ of the passengers.

Some interesting analysis can be performed based on the results discussed in this work. For instance, it is important to know the impact of closing an airport, for a given amount of hours. Furthermore, it is also interesting to have some insights on how long the transfers are. We can also analyze the ticket prices across the Brazilian regions. We plan to address these issues next.

\section{ACKNOWLEDGMENTS}

This research was funded by the authors' individual grants from grants from Conselho Nacional de Desenvolvimento Científico e Tecnológico (CNPq), Coordenação de Aperfeiçoamento de Pessoal de Nível Superior (CAPES), Instituto Nacional de Ciência e Tecnologia de Sistemas Micro e Nanoeletrônicos (INCT NAMITEC) and Fundação de Amparo à Pesquisa do estado de Minas Gerais (FAPEMIG).

\section{RESUMO}

A rede de transporte aéreo em um país tem um grande impacto na economia local, nacional e global. Neste artigo, analisamos a rede de transporte aéreo no Brasil através de métricas de redes complexas para o melhor entendimento de suas características. Em nossa análise, definimos redes compostas por voos nacionais ou internacionais. Também consideramos a rede onde ambos os tipos de voos são reunidos. Conclusões interessantes emergem da nossa análise. Por exemplo, o Aeroporto de Viracopos (cidade de Campinas) é o aeroporto mais central e conectado na rede de voos nacionais. Qualquer problema operacional neste aeroporto separa a rede brasileira em 6 subredes distintas. Mais ainda, a rede de conexão aérea nacional brasileira possui características de mundo pequeno e a rede das conexões nacionais segue uma distribuição de lei de potência. Portanto, nossa análise possibilita compreender a infraestrutura da rede de transporte aéreo Brasileira, trazendo um novo entendimento para ajudar a lidar com o rápido crescimento recente do uso da rede de transporte aéreo no Brasil.

Palavras-chave: Rede brasileira de Transporte Aéreo, ciência de redes, análise da estrutura da rede, redes complexas.

\section{REFERENCES}

ANAC - AgÊnCIA NaCional de AviaÇão Civil. 2013. Yearbook of Air Transport. Statistical and Economic Data 2012. Brasília, DF, Brazil 1: 7-50.

BAGLER G. 2008. Analysis of the airport network of India as a complex weighted network. Physica A 387(12): 2972-2980.

Bastian M, Heymann S And Jacomy M. 2009. Gephi: An open source software for exploring and manipulating networks. In: Proceedings of Internacional AAAI Conference on Weblogs and Social Media 1: 361-362.

Blondel V, Guillaume J, Lambiotte R and MeCh E. 2008. Fast unfolding of communities in large networks. J Stat Mech 1: 2-11.

BRIN S AND PAGE L. 1998. The anatomy of a large-scale hypertextual web search engine. Comput Netw ISDN Syst 30(1-7): 107-117.

Cheung D AND Gunes M. 2012. A complex network analysis of the united states air transportation. In Advances in Social Networks Analysis and Mining (ASONAM), 2012 IEEE/ACM International Conference on, p. 699-701. 
Costa TF, LOHMANn G AND OLIVEIRA AV. 2010. A model to identify airport hubs and their importance to tourism in Brazil. J Res Trans E 26(1): 3-11.

FORTUNATO S. 2010. Community detection in graphs. Phys Rep 486(3-5): 75-174.

GUIDA M AND MARIA F. 2007. Topology of the Italian airport network: A scale-free small-world network with a fractal structure? Chaos, Solitons \& Fractals 31(3): 527-536.

Guimer R, Mossa S, Turtschi A and Amaral LAN. 2005. The worldwide air transportation network: Anomalous centrality, community structure, and cities' global roles. Proc Natl Acad Sci USA 102(22): 7794-7799.

IÑIGUEZ G, KERTÉSZ J, KASKI KK AND BARRIO RA. 2009. Opinion and community formation in coevolving networks. Phys Rev E 80: 066119.
LI W AND CAI X. 2004. Statistical analysis of airport network of China. Phys Rev E 69: 04610-046112

NEWMAN MEJ. 2003. The structure and function of complex networks. SIAM Rev 45(2): 167-256.

NEWMAN MEJ. 2006. Modularity and community structure in networks. Proc Natl Acad Sci USA 103(23): 8577-8582.

Oliveira D, CARVAlho M AND Menezes R. 2013. Using network sciences to evaluate the brazilian airline network. In: Du DZ and Zhang G (Eds), Computing and Combinatorics. Lect Notes Comput Sc 7936: 849-858. Springer.

PACHECO R AND FERnANDES E. 2003. Managerial efficiency of brazilian airports. Transport Res A-Pol 37(8): 667-680.

REKA A AND BARABÁSI AL. 2002. Statistical mechanics of complex networks. Rev Mod Phys 74: 47-97. 